\title{
The Transient Pore Formed by Homologous Terminal Complement Complexes Functions as a Bidirectional Route for the Transport of Autocrine and Paracrine Signals across Human Cell Membranes
}

\author{
Juan A. Acosta, * Laura R. Benzaquen, ${ }^{\dagger}$ Daniel J. Goldstein,* \\ Magdalena T. Tosteson, * and José A. Halperin** \\ *Laboratory for Membrane Transport, Harvard Medical School, \\ Boston, Massachusetts, U.S.A. \\ ${ }^{\dagger}$ Department of Medicine, Beth Israel Hospital, Boston, Massachusetts, \\ U.S.A. \\ ${ }^{\ddagger}$ Department of Medicine, Brigham and Women's Hospital, Boston, \\ Massachusetts, U.S.A.
}

\begin{abstract}
Background: We have previously shown that the membrane attack complex (MAC) of complement stimulates cell proliferation and that insertion of homologous MAC into the membranes of endothelial cells results in the release of potent mitogens, including basic fibroblast growth factor (bFGF). The mechanism of secretion of bFGF and other polypeptides devoid of signal peptides, such as interleukin 1 (IL-1) is still an open problem in cell biology. We have hypothesized that the homologous MAC pore itself could constitute a transient route for the diffusion of biologically active macromolecules in and out of the target cells.

Materials and Methods: Human red blood cell ghosts and artificial lipid vesicles were loaded with labeled growth factors, cytokines and IgG, and exposed to homologous MAC. The release of the ${ }^{125}$ I-macromolecules was followed as a function of time. The incorporation of labeled polypeptides and fluorescent dextran (MW: 10,000) was measured in MAC-impacted human red
\end{abstract}

blood cells and human umbilical endothelial cells (HUVEC), respectively.

Results: Homologous MAC insertion into HUVEC resulted in the massive uptake of $10-\mathrm{kD}$ dextran and induced the release of bFGF, in the absence of any measurable lysis. Red blood cell ghosts preloaded with bFGF, IL- $1 \beta$, and the $\alpha$-chain of interferon- $\gamma$ (IFN- $\gamma$ ) released the polypeptides upon MAC insertion, but they did not release preloaded IgG. MAC-impacted ghosts took up radioactive IFN- $\gamma$ from the extracellular medium. Vesicles loaded with IL-1 released the polypeptide when exposed to MAC.

Conclusions: The homologous MAC pore in its nonlytic form allows for the export of cytosolic proteins devoid of signal peptides that are not secreted through the classical endoplasmic reticulum/Golgi exocytotic pathways. Our results suggest that the release, and perhaps the uptake, of biologically active macromolecules through the homologous MAC pore is a novel biological function of the complement system in mammals.

\section{INTRODUCTION}

A number of eucaryotic cell proteins of high biological relevance lack the signal sequences that usually guide protein translocation across the ER membrane and are secreted by routes

Address correspondence and reprint requests to: José A. Halperin, Laboratory for Membrane Transport, Harvard Medical School, 240 Longwood Avenue, C1-607, Boston, MA 02115 , U.S.A. other than the endoplasmic reticulum/Golgi (ER/G) pathway. They include basic fibroblast growth factor (bFGF) and acidic fibroblast growth factor (aFGF), cytokines (interleukin 1 [IL-1]), hormones $\left(\beta_{4}\right.$-thymosin and prothymo$\sin$ ), coagulation factors (the $\alpha$-chain of factor XIII), differentiation factors (the muscle lectin 1-14), and membrane structural proteins (amphoterin) $(1,2)$. 
Several mechanisms have been proposed to explain the export of these proteins across cell membranes. These mechanisms include the fusion of cytosolic vesicles with the cell membrane, transient disruption of the cell membrane permeability (3), the direct translocation of cytosolic polypeptides across the cell membrane, the concentration of peptides in cellular ectoplasm beneath regions of the plasma membrane which evaginate to form labile extracellular vesicles, and the existence of selective plasma membrane pores for protein transport. Among the latter are some ATPases of a superfamily of ATP-driven transport proteins which includes the multiple drug-resistant (MDR) protein and the cystic fibrosis conductance regulator, known as the cystic fibrosis transmembrane rectifier (CFTR) (1).

The terminal components of the complement system (C5b-9) form the membrane attack complex (MAC) pore. The MAC pore is a hollow amphipatic cylinder of effective internal radius of 5-7 nm layered with hydrophilic domains on the outside and hydrophobic domains in the interior. The deposition of the terminal complement components and the formation of the MAC pore can be triggered either by the immune or the nonimmune activation of the complement cascade $(4,5)$.

MAC insertion into the cell plasma membrane may have lytic or nonlytic outcomes depending on several factors, which include the number and size of the pores, the kinetics of opening and closing of the pores, the efficacy of the cell volume regulatory mechanisms in balancing the net cation gain through the pore, and the ability of the cell to shed MAC pore-enriched membranes. In turn, the number and size of the MAC pores inserted in a given cell are restricted by a family of complement regulatory proteins such as the decay-accelerating factor (DAF) and CD59 (6-8). Some of these complement regulatory proteins are species specific and only restrict MAC pore formation in their own species, a phenomenon known as homologous restriction (9). This explains why homologous cells can survive MAC insertion without apparent functional damage or lysis. In this nonlytic mode, the MAC causes nonlethal biological effects by inducing transient ionic fluxes, cytoskeletal changes, and exchange of signal molecules which may trigger complex physiological responses in the target cell. This secretory activation and its concomitant cellular effects are collectively known as the nonlytic actions of the MAC (10-13).

Recent work from our laboratory has uncovered an apparent link between homologous
MAC formation and cell proliferation. The incorporation of homologous MAC into the membranes of human umbilical vein endothelial cells (HUVEC) results in the release of bFGF and platelet-derived growth factor (PDGF), two autocrine and paracrine signals that induce proliferation of mesenchymal cells such as fibroblasts, endothelial cells, and smooth muscle cells (13). The observation that homologous MAC insertion induces the release of bFGF is particularly interesting, because this peptide lacks signal sequence and plays a crucial role in mammalian physiology and pathology. Mechanistically, the release of growth factors from MAC-impacted cells could be either secondary to the activation of cell secretory mechanisms (triggered, for instance, by the primary induction of $\mathrm{Ca}^{++}$fluxes) or be the result of the actual passage of cytosolic polypeptides through the MAC pore.

Other investigators have already documented the fact that the MAC pore allows the passage of macromolecules such as RNAase and inulin. These experiments were performed to characterize the exclusion size and other biophysical characteristics of the MAC pore. Here, we demonstrate that the homologous MAC pore is an exit route for cytosolic proteins devoid of signal peptides.

We propose that the homologous MAC pore is a transient route for the release and/or uptake of autocrine, paracrine, and/or endocrine signals across the plasma membrane, and provides a mechanism for the export of proteins devoid of signal peptides. Our results strongly suggest that the release and the uptake of biologically active macromolecules through the homologous MAC pore should be included among the physiological functions of the complement system in mammals.

\section{MATERIALS AND METHODS}

\section{Cell Culture}

HUVEC were cultured in 199/HBSS containing $20 \mathrm{mM} \mathrm{NaCO}$, $20 \mathrm{mM}$ HEPES, $2 \mathrm{mM}$ L-glutamine, $20 \%$ heat inactivated fetal calf serum (FCS), $50 \mu \mathrm{g} / \mathrm{ml}$ endothelial growth factor (EGF) (Biomedical Technologies, Inc., Stoughton, MA, U.S.A.) and $100 \mu \mathrm{g} / \mathrm{ml}$ heparin (Sigma Chemical Co., St. Louis, MO, U.S.A.). The HUVEC were seeded in 16-mm dishes (Costar Co., Cambridge, MA, U.S.A.) and 6.4-mm chamber slides and grown to confluence at $37^{\circ} \mathrm{C}$, in a mixture of $95 \%$ air and $5 \% \mathrm{CO}_{2}$. 


\section{Solutions}

All solutions were freshly prepared in ultrafiltered deionized $\mathrm{H}_{2} \mathrm{O}$. Lysis buffer (LB) contained $3 \mathrm{mM} \mathrm{MgCl}, 0.1 \mathrm{mM}$ EDTA, and $10 \mathrm{mM}$ HEPES, $\mathrm{pH}$ adjusted to $6.5\left(23^{\circ} \mathrm{C}\right)$ with HCL $1 \mathrm{~N}$; gelatin veronal buffer $\left(\mathrm{GVB}^{++}\right)$contained $140 \mathrm{mM}$ $\mathrm{NaCl}, 5 \mathrm{mM}$ sodium barbital, $0.15 \mathrm{mM} \mathrm{CaCl}_{2}$, and $0.5 \mathrm{mM} \mathrm{MgCl}_{2}$ with $0.1 \%$ gelatin, $\mathrm{pH} 7.4$. Choline washing solution (CWS) contained 150 $\mathrm{mM}$ choline chloride, I $\mathrm{mM} \mathrm{MgCl}_{2}$, and $10 \mathrm{mM}$ MOPS-Tris, pH 7.4 at $4^{\circ} \mathrm{C}$. Lactate dehydrogenase $(\mathrm{LDH})$ assay solution was comprised of 50 $\mathrm{ml}$ of freshly prepared $0.22 \mathrm{mM} \mathrm{NADH}$ in $0.1 \mathrm{M}$ phosphate buffer, $\mathrm{pH} 7.4$, Triton $\mathrm{X} 0.1 \%$, and 1 $\mathrm{mM}$ pyruvic acid. LDH $(1000 \mathrm{U} / \mathrm{ml})$ from beef heart was used, and FITC-dextran was of molecular weight $10 \mathrm{kD}$ (Sigma).

\section{Radiolabeled Polypeptides}

Four radiolabeled polypeptides were used: ${ }^{125} \mathrm{I}$ bFGF (MW: 17,200; SA: $106 \mu \mathrm{Ci} / \mu \mathrm{g}$ ), ${ }^{125} \mathrm{I}-\mathrm{IFN} \gamma$ (MW: 17,200; SA: $69.2 \mu \mathrm{Ci} / \mu \mathrm{g}$ ), ${ }^{125}$ I-IL- $\beta$ (human recombinant; $M W$ : 18,000; SA: $80-180$ $\mu \mathrm{Ci} / \mu \mathrm{g}$ ) (DuPont, Boston, MA, U.S.A.) and ${ }^{125} \mathrm{I}-$ anti-mouse IgG whole antibody (MW: 150,000; SA: 5-20 $\mu \mathrm{Ci} / \mu \mathrm{g}$ ) (Amersham Life Science, Arlington, IL, U.S.A.).

\section{Complement Reagents and Assays}

The complement assays were performed in isotonic $\mathrm{GVB}^{++}$. Human complement protein C5b6 was prepared as previously described (13) using purified human $\mathrm{C} 5$ and $\mathrm{C} 6$, factor $\mathrm{B}$, cobra venom factor $(\mathrm{CVF})$, and recombinant factor $\mathrm{D}$ (Advanced Research Technologies, San Diego, CA, U.S.A.). One unit of $\mathrm{C} 5 \mathrm{~b} 6$ was defined as the amount of $\mathrm{C} 5 \mathrm{~b} 6$ required to produce $50 \%$ lysis of $5 \times 10^{7}$ human red blood cells when incubated in a total volume of $300 \mu \mathrm{l}$ with C7 $(0.1 \mu \mathrm{g}), \mathrm{C} 8$ $(0.5 \mu \mathrm{g})$, and C9 $(0.5 \mu \mathrm{g})(14)$.

\section{Preparation and Efflux Experiments on Ghosts}

Fresh human red blood cells were obtained from normal blood anticoagulated with EDTA and washed three times in phosphate-buffered saline (PBS) (pH 7.4). Ghosts were prepared by a modification of a previously described method (15). Briefly, human red blood cells were washed three times in CWS and made $2 \%(\mathrm{v} / \mathrm{v})$ in LB. The solution was vigorously stirred for $30 \mathrm{~min}$ at $0^{\circ} \mathrm{C}$ and then centrifuged in a Sorvall RC-5B super- speed refrigerated centrifuge $(13,000 \mathrm{rpm} / 10$ $\min$ at $4^{\circ} \mathrm{C}$ ). The ghost pellet was resuspended in $2 \mathrm{ml}$ of $\mathrm{LB}$, and an aliquot of $3 \mathrm{M} \mathrm{KCl}$ was added to reach a final concentration of $150 \mathrm{mM}$. The ghosts were then stirred $5 \mathrm{~min} 0^{\circ} \mathrm{C}$, re-hemolyzed with $100 \mathrm{ml}$ of $\mathrm{LB}$, and the membranes recovered by centrifugation at $17,000 \mathrm{rpm}$ for 10 min. The membranes were washed three or four times, until the ghosts had a grayish white color (less than 5\% hemoglobin). The ghost pellet was resuspended in $2 \mathrm{ml}$ of cold LB, and enough radioactive polypeptide was added to reach a final concentration of $0.8 \mathrm{Ci} / \mathrm{ml}$. After loading, the ghost suspension was made $150 \mathrm{mM}$ with 3 $\mathrm{M} \mathrm{KCl}$, and the ghosts were resealed by incubating for $45 \mathrm{~min}$ at $37^{\circ} \mathrm{C}$. The resealed ghosts were sedimented by centrifugation $(27,000 \mathrm{~g} / 10 \mathrm{~min}$ at $4^{\circ} \mathrm{C}$ ) and washed five times with CWS in the presence of cold bFGF $(10 \mathrm{ng} / \mathrm{ml})$ or $0.2 \%$ bovine serum albumin (BSA) to remove untrapped markers. After the last wash, the ghost pellet was resuspended in $2 \mathrm{ml}$ of $\mathrm{GVB}^{++}$containing $-0.2 \%$ BSA to a final concentration of $\approx 5 \times 10^{8}$ ghosts/ $\mathrm{ml}$.

C5b6-7 ghosts $\left(5 \times 10^{8}\right.$ ghosts $\left./ \mathrm{ml}\right)$ were prepared by incubating the ghost suspension with 8 units of C5b6 and $5 \mu \mathrm{g} / \mathrm{ml}$ of purified C7 for 20 $\min$ at $37^{\circ} \mathrm{C}$. The ghosts carrying $\mathrm{C} 5 \mathrm{~b} 67$ were washed once with $\mathrm{GVB}^{++}$and resuspended to the original volume. MAC formation was carried out by incubating the ghosts at $37^{\circ} \mathrm{C}$ with 5 $\mu \mathrm{g} / \mathrm{ml}$ of $\mathrm{C} 8$ and $5 \mu \mathrm{g} / \mathrm{ml}$ of C9. After incubation, aliquots were centrifuged in a MicroSpin 24 Sorvall $\left(14000 \mathrm{rpm} / 5 \mathrm{~min}\right.$ at $\left.17^{\circ} \mathrm{C}\right)$ and the supernatants collected to measure ${ }^{125} \mathrm{I}$ in a $\gamma$ counter (Packard Instruments, Meriden, CT, U.S.A.) and hemoglobin absorbance in an enzyme-linked immunosorbent assay (ELISA) plate reader (414 nm) (Biorad, Hercules, CA, U.S.A.). Release of radioactive markers was determined by counting samples of the supernatant fluids as well as the residual ghost pellets. The amount of marker released was expressed as the percentage of the total radioactivity trapped in the original suspension ghosts after resealing.

\section{Monolamellar Lipid Vesicles Preparation}

Vesicles were prepared by mixing Asolectin (60 $\mathrm{mg} / \mathrm{ml}$ in $150 \mathrm{mM} \mathrm{NaCl}$ ) with ${ }^{14} \mathrm{C}$-oleic acid (1.8 $\mu \mathrm{Ci} / \mathrm{ml}$ of vesicles; $\mathrm{SA}: 0.1 \mu \mathrm{Ci} / \mu \mathrm{l}$ ) (DuPont NEN, Boston, MA, U.S.A.) (16). After vortexing the sample for $1 \mathrm{~min}$, enough radioactive polypeptide $\left({ }^{125} \mathrm{I}-\mathrm{IL}-1\right)$ was added to reach a final concentration of $0.8 \mu \mathrm{Ci} / \mathrm{ml}$. The mixture was 
stained with a small amount of Oxanol (Molecular Probes, Eugene, OR, U.S.A.) to label the vesicles and sonicated until the preparation was translucent. In order to obtain unilamellar vesicles, multilamellar vesicles were subjected to 10 freezing and thawing cycles, then passed 10 times through a 0.1- $\mu \mathrm{m}$ polycarbonate filter (Nucleopore Corp., Pleasanton, CA, U.S.A.), and finally inserted into a LiposoFast-Basic (Avestin Inc., Ottawa, Canada).

MAC formation in the vesicles was carried out by incubating the vesicles at $37^{\circ} \mathrm{C}$ with 8 units of C5b-6, C7, C8, and C9 in a sequence and concentration similar to those described for ghosts. After $30 \mathrm{~min}$, aliquots were collected and centrifuged in an air ultracentrifuge (Beckman Instruments, Palo Alto, CA, U.S.A.) at 60,000 rpm for $30 \mathrm{~min}$. Supernatant was used to measure ${ }^{125} \mathrm{I}$ as an indicator of $\mathrm{IL}-1$ release, and ${ }^{14} \mathrm{C}$ as an indicator of lipid vesicles remaining in the supernatant.

\section{Influx Experiment in Human Red Blood Cells}

The influx of labeled polypeptides into human red blood cells in the presence and absence of MAC pore lesions was conducted essentially as described before with minor modifications (17).

\section{Incorporation of $10 \mathrm{kD}$ FITC-Dextran in HUVEC}

On the second passage HUVEC were grown to confluence in either chamber slides or $16-\mathrm{mm}$ dishes $\left(37^{\circ} \mathrm{C}, 5 \% \mathrm{CO}_{2}\right)$, and exposed sequentially to $100 \mu \mathrm{l}$ of $\mathrm{C} 5 \mathrm{~b} 6$ protein containing 6 hemolytic units and $100 \mu \mathrm{l}$ of $\mathrm{C} 7(30 \mu \mathrm{g} / \mathrm{ml})$ containing 10 -kD fluorescent dextran $(10 \mathrm{mg} / \mathrm{ml})$. Three minutes later, $100 \mu \mathrm{l}$ of C8-C9 (30 $\mu \mathrm{g} / \mathrm{ml}$ each) were added. After $15 \mathrm{~min}$ of incubation at $37^{\circ} \mathrm{C}$, the HUVEC were washed four times in Dulbecco's modified Eagle's medium (DMEM) without phenol red $-0.1 \%$ BSA, fixed with paraformaldehyde $2 \%$, and immediately examined using a fluorescence microscope (Axiophot, Zeiss). Parallel experiments were performed on HUVEC seeded on 24-well plates to determine LDH release under the same conditions (18). Saponin-treated cells were used as a positive control for cell lysis and release of $\mathrm{LDH}$.

\section{RESULTS}

\section{Homologous MAC Insertion Does Not Cause Cell Lysis}

Previous work has established that HUVEC release bFGF to the culture medium when targeted with purified human terminal complement components which form homologous MAC pores in the cell membrane (13). One possible explanation for this phenomenon could be that bFGF is released into the conditioned media because a small population of cells undergo colloid-osmotic lysis upon homologous MAC insertion. To exclude this possibility, we analyzed the relationship between cell lysis and bFGF release in homologous MAC-impacted cells. Release of $\mathrm{LDH}$ and uptake of trypan blue were measured to estimate the amount of cell lysis produced by homologous MAC (18). Exposure of the cells to homologous MAC at concentrations that released a significant amount of bFGF neither induced the release of $\mathrm{LDH}$ nor the uptake of trypan blue (data not shown). Furthermore, follow-up for up to $48 \mathrm{~h}$ after treatment with the homologous MAC failed to detect any significant morphologic differences when MAC-treated and control cells were compared. In contrast, saponin-treated cells released LDH to the supernatant and incorporated trypan blue. These results indicate that release of bFGF from HUVEC is a nonlethal effect of the homologous MAC that occurs without cell lysis.

\section{FITC-Dextran Uptake by HUVEC Impacted with Homologous MAC}

Permeability of the MAC pore to dextrans of different molecular weights has been described in a heterologous system (sheep red blood cellshuman complement) (19). To investigate whether the homologous MAC pore at nonlytic concentrations could be a bidirectional pathway for the diffusion of macromolecules across cell membranes, HUVEC were exposed to human terminal complement components in the presence of $10 \mathrm{kD}$ FITC-dextran. The whole population of HUVEC treated with sublytic homologous MAC trapped fluorescent dextran (Fig. 1). In contrast, no fluorescence was detected in either control cells exposed for the same time interval to a similar concentration of FITC-dextran in the absence of MAC, or in HUVEC exposed to the terminal complement components in a sequence that does not induce formation of the MAC (not shown). These controls ruled out any nonspecific adsorption of the fluorescent compound occurring independently of the homologous MAC formation. No evidence of cell lysis was detected, as measured by the release of LDH. These results indicate that upon MAC formation HUVEC become permeable to 10-kD FITC-dextran. 


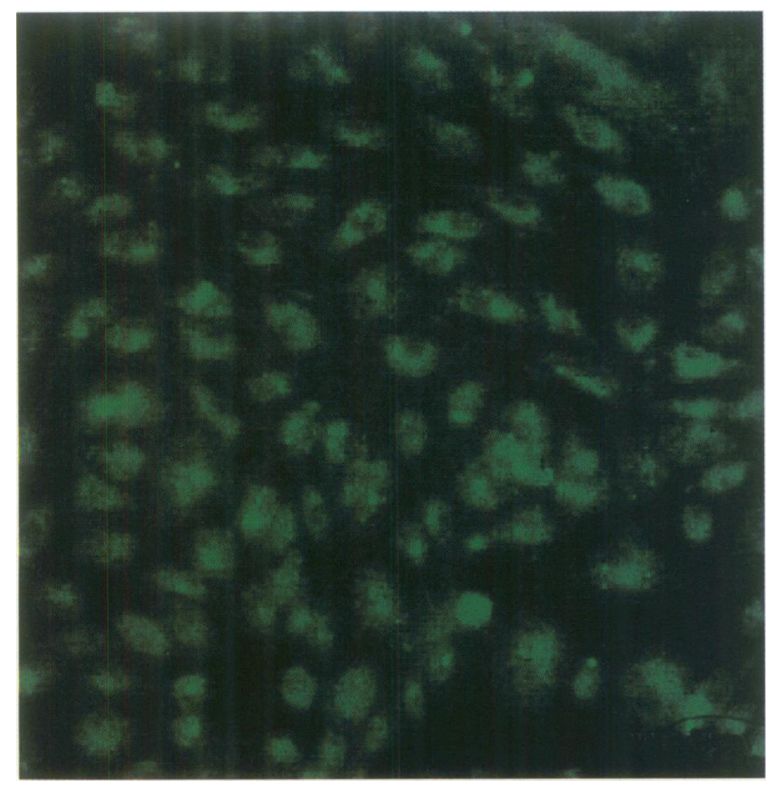

FIG. 1. Uptake of 10-kD FITC-Dextran by HUVEC treated with homologous MAC

HUVEC exposed to 6 units of homologous MAC become permeable to $10-\mathrm{kD}$ FITC-dextran. The whole population of HUVEC incorporated the fluorescent probe. There was no FITC-dextran incorporation either in the absence of terminal complement components, or in the presence of purified complement proteins in combinations that do not form the homologous MAC $(20 \times)$.

\section{Release of Peptides from Ghosts and Vesicles}

To determine whether the homologous MAC pore itself could be a route for diffusion of molecules across cell membranes, it became essential to minimize MAC-induced colloidosmotic cell lysis as an alternative mechanism for the release of compounds from MAC-targeted cells. White ghosts and vesicles are two experimental systems that fulfill this requirement because their internal and external compositions can be adjusted to avoid colloidosmotic lysis, and they can be loaded at will with any desired macromolecule. These systems have the additional advantage of eliminating any possible fluctuation in the release of entrapped molecules after insertion of MAC due to the active shedding of pores that normally occurs in nucleated cells after MAC insertion into their membranes. The inserted homologous MAC channels remain in ghosts for at least $24-48 \mathrm{hr}(11,20)$; and vesicles are metabolically inert and lack cytoskeleton proteins involved in shedding MAC pores (12).

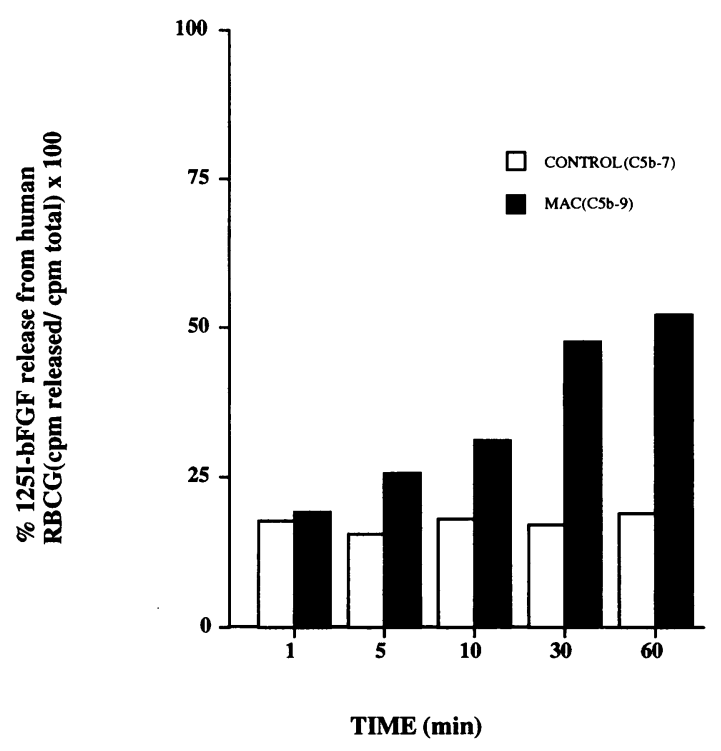

FIG. 2. bFGF release from ghosts

Ghosts $\left(5 \times 10^{8} / \mathrm{ml}\right)$ containing ${ }^{125} \mathrm{I}$-bFGF were exposed to either C5b6-7 or C5b-9 (8 units) for up to $60 \mathrm{~min}$. Aliquots were removed and centrifuged for 5 min. ${ }^{125}$ I-bFGF was measured in the supernatant. The amount of radioactive tracer released by the MAC is expressed as the percentage of the total radioactivity in the original ghosts. The data points were calculated from the means of triplicate samples and displayed a variation of $<10 \%$.

\section{Release of bFGF from Ghosts}

To investigate whether human bFGF could move across the homologous MAC pore, we measured the release of labeled bFGF from ghosts prepared as described in Materials and Methods.

In the absence of homologous MAC there is no significant release of ${ }^{125} \mathrm{I}-\mathrm{bFGF}$. The small amount of ${ }^{125} \mathrm{I}-\mathrm{bFGF}$ found in the supernatant came from the detachment of ${ }^{125}$ I-bFGF nonspecifically adsorbed to the cell membrane. This radioactive bFGF can be chased and released into the extracellular medium by cold bFGF. Upon addition of the terminal complement components, ${ }^{125} \mathrm{I}-\mathrm{bFGF}$ is progressively released from the ghosts and reaches a plateau after approximately 60 min (Fig. 2).

Under our experimental conditions, there was no colloidosmotic lysis of the ghosts. The residual hemoglobin concentration in the supernatant of control and homologous MAC-treated ghosts were the same (Table 1). Furthermore, our ghost preparations did not show any evidence of leakiness, since in the absence of the 
TABLE 1. Release of residual hemoglobin from ghosts

\begin{tabular}{lcc}
\hline & $\mathbf{5} \min (\%)$ & $\mathbf{3 0} \min (\%)$ \\
\hline Control ghosts & $6 \pm 2$ & $7 \pm 3$ \\
C5b-7 ghosts & $6 \pm 2$ & $7 \pm 2$ \\
MAC & $6 \pm 2$ & $7 \pm 2$ \\
\hline
\end{tabular}

Ghosts were exposed to C5b-7 or C5b-9 (8 units) and the amount of hemoglobin released into the medium was measured by the absorbance at $414 \mathrm{~nm}$. Results are expressed as the percentage of hemoglobin released into the supernatant. The total residual hemoglobin inside the ghosts after total lysis with a detergent is $100 \%$. Numbers represent averages $\pm 1 \mathrm{SD}$ of two experiments performed in triplicate.

MAC pore there was release of neither radioactive bFGF nor hemoglobin to the medium.

\section{Release of IL-1 from Ghosts}

To determine whether the observed release of bFGF represented a general pathway for the release of polypeptides without a signal sequence, we examined the effect of the terminal complement components on ghosts loaded with IL-1.

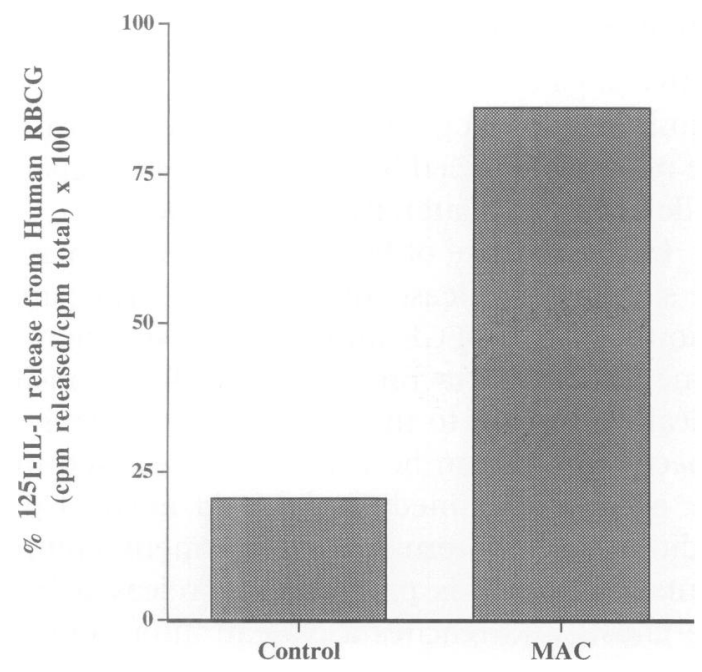

FIG. 3. Release of IL-1 $\beta$ from ghosts

Ghosts $\left(5 \times 10^{8} / \mathrm{ml}\right)$ containing ${ }^{125} \mathrm{I}-\mathrm{IL}-1 \beta$ were exposed to either $\mathrm{GVB}^{++}$or C5b-9 (8 units) for 60 min and subsequently centrifuged for $5 \mathrm{~min} .{ }^{125} \mathrm{I}-$ IL- $1 \beta$ was measured in the supernatant. The amount of tracer released by the MAC is expressed as the percentage of the total radioactivity in the original ghosts.

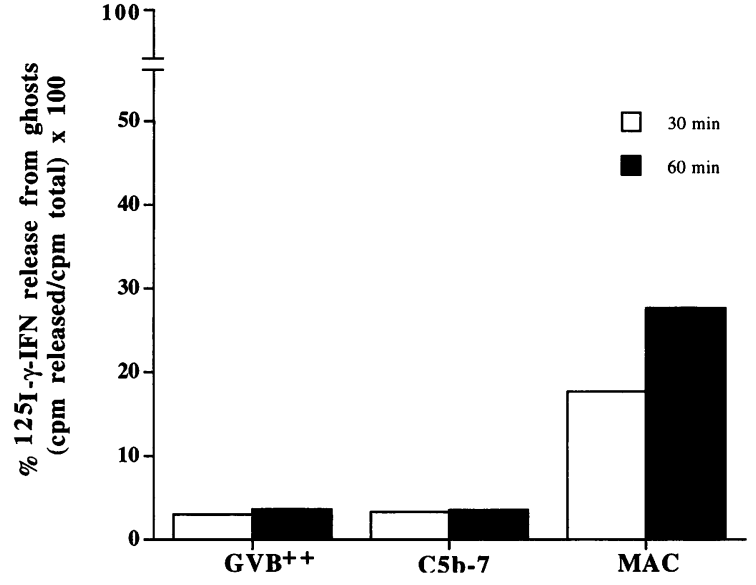

FIG. 4. Release of IFN $\boldsymbol{\gamma}$ from ghosts

Ghosts $\left(5 \times 10^{8} / \mathrm{ml}\right)$ containing ${ }^{125} \mathrm{I}$-IFN $\gamma$ were exposed to $\mathrm{GVB}^{++}$, C5b6-7, or C5b-9 (8 units) for 30 and $60 \mathrm{~min}$, and subsequently centrifuged for $5 \mathrm{~min}$. ${ }^{125} \mathrm{I}$-IFN $\gamma$ was measured in the supernatant. The amount of tracer released by the MAC is expressed as the percentage of the total radioactivity in the original ghosts.

${ }^{125}$ I-IL-1 was also released from ghosts impacted by homologous MAC. Figure 3 shows that more than $90 \%$ of the IL-1 trapped inside the ghosts was released upon exposure to homologous MAC.

\section{Homologous MAC Pore Restricts by Size and Not by Fold}

Since bFGF and IL-1 are of similar molecular weight and have an identical fold made up exclusively of $\beta$ sheets (21), it was necessary to determine whether the homologous MAC pore restricts diffusion of macromolecules on the basis of tridimensional structure or mass. The $20-\mathrm{kD}$ $\alpha$-subunit of $\alpha$-IFN $\gamma$ is primarily an $\alpha$-helical molecule, devoid of $\beta$ sheets (22). Ghosts loaded with ${ }^{125}$ I- $\alpha$-IFN $\gamma$ and exposed to 8 units of homologous MAC released up to $25-30 \%$ of the radioactive peptide in a time-dependent fashion. In the absence of terminal complement components there was practically no release (Fig. 4). These experiments suggest that $\beta$ sheet folding is not a requirement for transport across the homologous MAC pore. On the other hand, ${ }^{125} \mathrm{I}$ IgG (150 kD)-loaded ghosts did not release the protein upon the insertion of the homologous MAC (Fig. 5). These results show that the homologous MAC pore restricts by size and not by fold. 


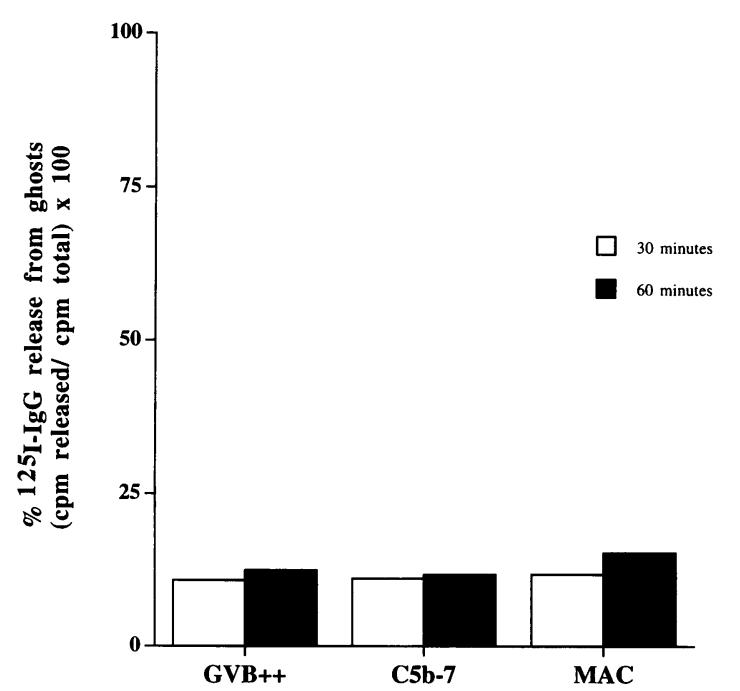

FIG. 5. Release of IgG from ghosts

Ghosts $\left(5 \times 10^{8} / \mathrm{ml}\right)$ containing ${ }^{125} \mathrm{I}-\mathrm{IgG}$ were exposed to either $\mathrm{GVB}^{++}$, C5b6-7, or C5b-9 (8 units) for 30 and $60 \mathrm{~min}$, and subsequently centrifuged for 5 min. ${ }^{125} \mathrm{I}$-IgG was measured in the supernatant. The amount of tracer released by the MAC is expressed as the percentage of the total radioactivity in the original ghosts.

\section{${ }^{125}$ I-IFN $\gamma$ Uptake into Human Red Blood Cells}

Previous experiments indicate that homologous MAC pores allow for the outward diffusion of polypeptides and the influx of $10-\mathrm{kD}$ dextran. To investigate further whether homologous MAC pores could serve as a bidirectional avenue for the diffusion of macromolecules into as well as out of

TABLE 2. Influx of ${ }^{125}$ I-IFN $\gamma$ into human red blood cells

cpm/l cells $\left(10^{6}\right)$

\begin{tabular}{ll}
\hline Control & 0 \\
C5b-7 & 3.1 \\
MAC & 6.2 \\
\hline
\end{tabular}

Human red blood cells were exposed to $\mathrm{C} 5 \mathrm{~b}-7$ or $\mathrm{C} 5 \mathrm{~b}-\mathrm{9}$ ( 0.3 units) in the presence of ${ }^{125}$ I-IFN $\gamma$. Uptake of the radiolabeled polypeptide was measured after $30 \mathrm{~min}$. Influx was calculated from the hemoglobin of the sample lysate, the hematocrit of the initial cell suspension, and the specific activity of the tracer in the influx medium. Results are expressed as cpm/l of cells and represent averages of two experiments performed in duplicate.

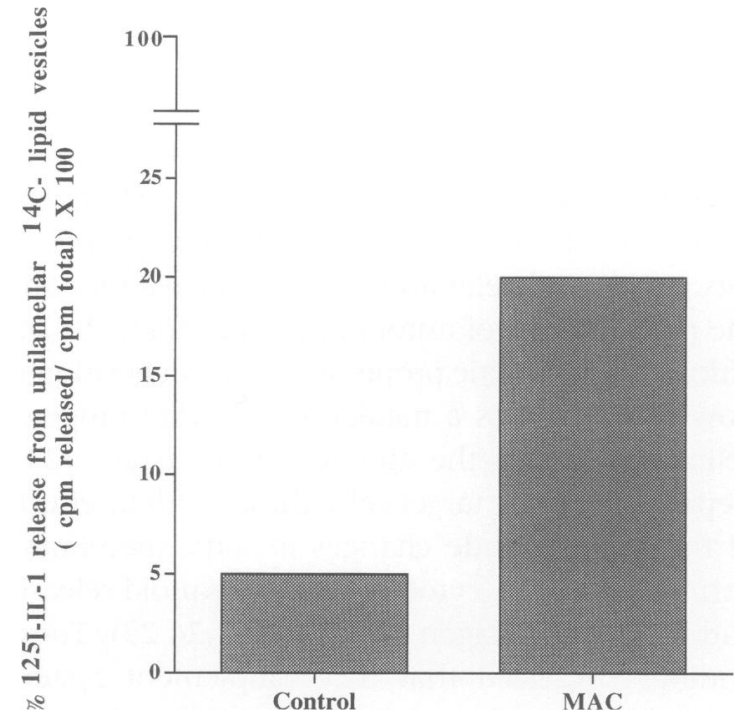

FIG. 6. Release of IL- $1 \beta$ from lipid vesicles Vesicles containing ${ }^{125} \mathrm{I}-\mathrm{IL}-\mathrm{l} \beta$ were exposed to 8 units of C5b6-9 for 30 min and subsequently centrifuged at $60,000 \mathrm{rpm}$ for $30 \mathrm{~min} .{ }^{125} \mathrm{I}-\mathrm{IL}-1 \beta$ was measured in the supernatant. The amount of tracer released by the MAC is expressed as the percentage of the total radioactivity in the original vesicles. The number of vesicles in each experimental sample was estimated from the amount of ${ }^{14} \mathrm{C}$.

cells, influx of ${ }^{125} \mathrm{I}-\alpha$-IFN $\gamma$ into human red blood cells was measured before and after exposure to homologous MAC. Comparable experiments could not be carried out with bFGF due to the high nonspecific binding of bFGF to the red blood cell surface.

Table 2 shows that the uptake of ${ }^{125}$ I- $\alpha$-IFN $\gamma$ into MAC-treated ghosts was 2 -fold higher than in control ghosts exposed only to $\mathrm{C} 5 \mathrm{~b}-7$. These results confirm that the homologous MAC pore allows for the bidirectional movement of macromolecules.

\section{Release of IL-1 from Vesicles}

After $30 \mathrm{~min}$ of exposure to homologous MAC, ${ }^{14} \mathrm{C}$-oleic acid-labeled vesicles loaded with ${ }^{125} \mathrm{I}$ IL-1 released five times more peptide than control vesicles (Fig. 6). No ${ }^{14} \mathrm{C}$ counts were detected in the supernatants after centrifugation at $60,000 \mathrm{rpm}$ for $30 \mathrm{~min}$, indicating that (i) all vesicles were spun down, and (ii) MAC impaction did not induce vesicle lysis and/or disruption of their lipid membrane. Since the MAC pore is the only pathway out of the lipid vesicles, these results support the view that the MAC pore was the route for the efflux of this cytokine to the extracellular milieu. 


\section{DISCUSSION}

The complement system was initially conceptualized as a proteolytic cascade accessory to the immune system specialized in the destruction of microbes and extracellular parasites. Then the system was found to contribute to the inflammatory process, platelet and mast cell activation, and the pathogenesis of autoimmune disorders. In addition to its cytolytic properties, MAC deposition is now recognized as a mediator of a wide range of cellular events in the absence of cell death (23). Depending on the target cells, these nonlytic effects of the MAC include changes in ionic membrane permeability (17), cytokine and eicosanoid release, and increased collagen synthesis $(17,24,25)$. These findings suggested that the complement system could have previously unsuspected functions in mammalian pathology, a concept that is now well accepted and has been documented by several laboratories. The finding that deposition of complement terminal components in human pathological lesions is usually associated with cell proliferation and neovascularization $(26-30)$ led us to the discovery that the MAC stimulates cell proliferation (14) and that homologous MAC insertion into HUVEC induces the release of bFGF and PDGF. These findings together with the recent demonstration that the MAC induces the release of MCP-1 (8 $\mathrm{kD})$ from smooth muscle cells, provide strong evidence for the existence of a functional link between the deposition of terminal complement components and cell proliferation in pathological processes $(13,31)$.

The results presented in this article show that (i) upon insertion of the MAC pore, bFGF and IL- 1 (two polypeptides devoid of signal peptides) as well as the $\alpha$-chain of IFN $\gamma$, are released from ghost and lipid vesicles; (ii) the MAC pore restricts by mass, not by molecular shape; and (iii) the MAC pore allows the influx of 10-kD FITCdextran into HUVEC, and $\alpha$-IFN $\gamma$ into red blood cells, with no evidence of cell lysis.

The diffusion of ions and macromolecules in and out of red blood cells, ghosts, and vesicles through the MAC pore in heterologous systems is a well known phenomenon and has been extensively studied $(10,11,20,32-35)$. Experiments with heterologous systems helped to define the biophysical properties of the pore such as molecular dimensions, sieving characteristics, and permeability, but were not intended to explore whether the MAC pore had any physiological relevance. Cells impacted with heterologous
MAC generally lyse, and many of the mechanisms that modulate and limit MAC pore formation in the membrane, as well its kinetic properties, are inoperant in heterologous systems.

Under our experimental conditions, biologically active polypeptides were released by homologous MAC from HUVEC, ghosts, and vesicles without lysis. HUVEC exposed to the terminal complement components released bFGF but not $\mathrm{LDH}$, a marker of cell lysis. Ghosts impacted by homologous MAC released bFGF, IL-1, and IFN, but released neither their residual hemoglobin nor entrapped IgG. The fact that MAC-induced release of intracellularly trapped molecules from ghosts was dependent on the size of the intracellular molecule further confirms that lysis was not involved. ${ }^{14} \mathrm{C}$-oleic acid was not found in the supernatants of MAC-treated vesicles, indicating that the insertion of terminal complement components did not lyse the liposomes. Since ghosts and lipid vesicles are devoid of a functional cytoskeleton, the release of polypeptides cannot be attributed to the active shedding of peptide-enriched membrane fragments.

It is highly improbable that our results reflect unspecific leakage of the macromolecules trapped either in the ghosts or the vesicles. Vesicles are very stable and preserve the trapped molecules for a long period of time without any detectable leak (12). Moreover, ghosts are remarkably nonleaky, and it is precisely this characteristic that makes them useful model systems for biochemical, morphological, and membrane transport studies (15).

If MAC-induced lysis is excluded as a mechanism of bFGF and IL-1 release from MAC-targeted ghosts, the only alternative to diffusion through the MAC pore itself would be a membrane transporter, which, upon activation by some complement factor, would carry the peptides across the membrane. Since release was only observed in the presence of all terminal complement components added in a sequence that forms the MAC, the putative transporter would be stimulated by insertion of the MAC and be inactive under all other experimental conditions tested in our experiments. This unlikely possibility could explain only the results with ghosts but not those obtained in vesicles because they do not contain any membrane protein that could act as a transporter.

Our results confirm observations published by other authors showing that diffusion of macromolecules through the MAC pore is bidirectional and restricted by their mass. bFGF, IL- 1 , and $\alpha$-IFN $\gamma$ are released from ghosts upon the 
addition of MAC, but IgG is not. Furthermore, we showed that the MAC pore does not restrict by fold, since it allows the passage of bFGF and IL-1, two purely $\beta$ sheet polypeptides, and $\alpha$-IFN $\gamma$, a primarily $\alpha$-helical molecule, devoid of $\beta$ sheets.

The homologous MAC pore may also function as a bidirectional route for macromolecules. We were able to load homologous MAC-impacted HUVEC with 10-kD FITC-dextran, and homologous MAC-impacted human red blood cells with $\alpha$-IFN $\gamma$, without producing cell lysis.

The complement system seems to be ideally suited for facilitating the release of intracellular polypeptides and the uptake of extracellular signals. It is well known that the system is not only activated by immune mechanisms but also by many non-immune conditions and agents, including hypoxia, tissue damage, lipo-polysaccharides, mannan binding protein, $\mathrm{C}$-reactive protein, serum amyloid $\mathrm{P}$ components, $\beta$-amyloid peptide, and cholesterol crystal. All of these can trigger the activation of the complement cascade leading to the deposition of C5b-9 (23). The complement proteolytic cascade, as well as the deposition of the homologous MAC pore, are tightly regulated by soluble and membrane regulatory proteins (6). Insertion of the homologous MAC pore activates the classical ER/G exocytotic mechanism and, as we have shown previously and confirmed here, also creates a pathway for the export of cytosolic proteins lacking conventional signal peptides. Furthermore, the life span of the pore in homologous cells is very short ( 2 to $7 \mathrm{~min}$ ) because the insertion of the homologous MAC pore induces cytoskeletal changes that result in the active shedding of pore-enriched membrane segments (36). This short life span of the MAC pore is totally compatible with our previous results, which have shown release of bFGF from HUVEC within 1 min after MAC insertion. Moreover, proteins without signal peptides tend to be concentrated in the ectocytosol (2) immediately below the plasma membrane. This cellular location would increase the efficient concentration for diffusion and make the proteins readily available for release through the MAC pore. All these characteristics seem to be ideally suited for a localized, transitory, and reversible mechanism of bidirectional transport.

Taken together, the present results strongly support the hypothesis that the homologous MAC pore could be a route for the release and/or uptake of biologically active polypeptides, including those lacking a signal peptide. If this property of the homologous MAC pore occurs in vivo, the opening of transient pores for the transit of biologically active molecules across cell membranes would constitute a novel, previously unsuspected role of the complement system in animal biology.

\section{ACKNOWLEDGMENTS}

The authors are grateful to Dr. Daniel C. Tosteson for insightful comments on the manuscript, to Dr. T. W. Smith for continuous and enthusiastic support, and to Dr. M. A. Gimbrone, Jr., for kindly providing the HUVEC.

\section{REFERENCES}

1. Muesch A, Hartmann E, Rohde K, Rubartelli A, Sitia R, Rapoport TA. (1990) A novel pathway for secretory proteins. TIBS 15: 8688.

2. Barondes SH, Cooper DNW. (1990) Evidence for export of a muscle lectin from cytosol to extracellular matrix and for a novel secretory mechanism. J. Cell Biol. 10: 1681-1691.

3. McNeil PL, Muthukrishanan L, Warder E, D'Amore PA. (1989) Growth factors are released by mechanically wounded endothelial cells. J. Cell Biol. 109: 811-822.

4. Morgan BP. (1990) Complement: Clinical Aspects and Relevance to Disease. Academic Press, London.

5. Bhakdi S, Tranum-Jensen J. (1991) Complement lysis: A hole is a hole. Immunol. Today 12: $318-320$.

6. Liszewski MK, Farries TC, Lublin, DM, Rooney IA, Atkinson JP. (1996) Control of the Complement System. Adv. Immunol. 61: 201-283.

7. Lublin DM, Atkinson JP. (1989) Decay-accelerating factor, biochemistry, molecular biology and function. Annu. Rev. Immunol. 7: 35-58.

8. Davies A, Simmons L, Hale G, et al. (1989) CD59, an Ly-6-like protein expressed in human lymphoid cells, regulates the action of the complement membrane attack complex on homologous cells. J. Exp. Med. 170: 637654.

9. Lachmann PJ. (1991) The control of Homologous Lysis. Immunol. Today 12: 312-315. 
10. Giavedoni EB, Chow YM, Dalmasso AP. (1979) The functional size of the primary complement lesion in resealed erythrocyte membrane ghosts. J. Immunol. 122: 240-244.

11. Ramm LE, Mayer MM. (1980) Life-span and size of the trans-membrane channel formed by large doses of complement. J. Immunol. 124: $2281-2287$.

12. Malinski J, Nelsestuen G. (1989) Membrane permeability to macromolecules mediated by the membrane attack complex. Biochemistry 28: 61-70.

13. Benzaquen LR, Nicholson-Weller A, Halperin JA. (1994) Terminal complement proteins C 5b-9 release basic fibroblast growth factor and platelet-derived growth factor from endothelial cells. J. Exp. Med. 179: 985-992.

14. Halperin JA, Taratuska A, Nicholson-Weller A. (1993) Terminal complement complex C5b-90 stimulates mitogenesis in 3T3 cells. J. Clin. Invest. 91: 1974-1978.

15. Bjerrum PJ. (1979) Hemoglobin-depleted human erythrocyte ghosts: characterization of morphology and transport functions. $J$. Membr. Biol. 48: 43-67.

16. MacDonald RC, MacDonald RI, Menco BPM, Takeshita K, Subbarao NK, Hu L-R. (1991) Small-volume extrusion apparatus for preparation of large, unilamellar vesicles. Biochim. Biophys. Acta 1061: 297-303.

17. Halperin JA, Nicholson-Weller A, Brugnara C, Tosteson DC. (1988) Complement induces a transient increase in membrane permeability in unlysed erythrocytes. J. Clin. Invest. 82: 594-600.

18. Jatinder C, Joist JH, Webster R. (1987) Loss of ${ }^{51}$ chromium, lactate dehydrogenase, and ${ }^{111}$ indium as indicators of endothelial cell injury. Lab. Invest. 57: 578-584.

19. Sauer H, Pratsch L, Tschopp J, Bhakdi S, Peters R. (1991) Functional size of complement and perforin pores compared by confocal laser scanning microscopy and fluorescence microphotolysis. Biochim. Biophys. Acta 1063: 137-146.

20. Ramm LE, Whitlow MB, Mayer MM. (1982) Size of the transmembrane channels produced by complement proteins C5b-8. J. Immunol. 129: 1143-1146.

21. Zhang J, Cousens LS, Barr PJ, Sprang SR. (1991) Three-dimensional structure of human basic fibroblast growth factor, a structural homolog of interleukin 1 $\beta$. Proc. Natl. Acad. Sci. U.S.A. 88: $3446-3450$.
22. Ealick SE, Cook S, Vijak-Kumar S, et al. (1991) Three-dimensional structure of recombinant human interferon gamma. Science 252: 698-702.

23. Morgan BP. (1995) Physiology and pathophysiology of complement: Progress and trends. Crit. Rev. Clin. Lab. Sci. 32: 265-298.

24. Cybulsky AV, Monge JC, Papillon J, McTavish AJ. (1995) Complement C5b-9 activates cytosolic phospholipase A2 in glomerular epithelial cells. Am. J. Physiol. 269: F739-F749.

25. Morgan BP, Luzio JP, Campbell AK. (1986) Intracellular $\mathrm{Ca}^{++}$in complement membrane attack. Cell Calcium 7: 399-411.

26. Morgan BP. (1989) Complement membrane attack on nucleated cells: Resistance, recovery and non-lethal effects. Biochem. J. 264: $1-14$.

27. Baldwin III WM, Pruitt SK, Brauer RB, Daha MR, Sanfilippo F. (1995) Complement in organ transplantation. Transplantation 59: 797808.

28. Rosen RD. (1993) Complement activation in cardiac disease. In: Curtis MJ (ed). Immunopharmacology of the Heart. Academic Press, London, pp. 75-86.

29. Stahl GL, Reenstra WR, Frendl G. (1995) Complement-mediated loss of endotheliumdependent relaxation of porcine coronary arteries. Role of the terminal membrane attack complex. Circ. Res. 76: 575-583.

30. Falk RJ, Sisson SP, Dalmasso AP, Kim Y, Michael AF, Vernier RL. (1987) Ultrastructural localization of the membrane attack complex of complement in human renal tissues. Am. J. Kidney Dis. 9: 121-128.

31. Torzewski J, Oldroyd R, Lachmann P, Fitzsimmons C, Proudfoot D, Bowyer D. (1996) Complement-induced release of monocyte chemotactic protein-1 from human smooth muscle cells. A possible initiating event in atherosclerotic lesion formation. Arterioscler. Thromb. Vasc. Biol. 16: 673-677.

32. Sauer H, Pratsch L, Fritzsch G, Bhakdi S, Peters R. (1991) Complement pore genesis observed in erythrocyte membranes by fluorescence microscopic single-channel recording. Biochem. J. 276: 395-399.

33. Simone CB, Henkart P. (1982) Inhibition of marker influx into complement-treated resealed erythrocyte ghosts by anti-C5. J. Immunol. 128: 1168-1175. 
34. Sims PJ, Lauf PK. (1978) Steady-state analysis of tracer exchange across the C5b-9 complement lesion in a biological membrane. Proc. Natl. Acad. Sci. U.S.A. 75: 56695673.

35. Michaelis DW, Abramovitz AS, Hammer CH, Mayer MM. (1976) Increased ion permeability of planar lipid bilayer membranes after treatment with the C5b-9 cytolytic attack mechanism of complement. Proc. Natl. Acad. Sci. U.S.A. 73: 2852-2856.

36. Carney DF, Koski CL, Shin ML. (1985) Elimination of terminal complement intermediates from the plasma membrane of nucleated cells: the rate of disappearance differs for cells carrying C5b-7 or C 5 b-8 a mixture of $\mathrm{C} 5 \mathrm{~b}-8$ with a limited number of $\mathrm{C} 5 \mathrm{~b}-9$. J. Biol. Chem. 134: 1804-1809.

Contributed by K.F. Austen. Accepted on August 13, 1996. 